\title{
Perhitungan Integral Lipat menggunakan Metode Monte Carlo
}

\author{
Nugroho Agus Haryono \\ Program Studi Teknik Informatka \\ Universitas Kristen Duta Wacana Yogyakarta \\ Email: nugroho@ukdw.ac.id
}

\begin{abstract}
Abstrak:
Perhitungan Integral lipat suatu fungsi kontinu dengan dua variabel, $z=f(x, y)$, merupakan permasalahan deterministik yang dapat diselesaikan dengan metode determisitik maupun metode stokastik. Metode Monte Carlo merupakan salah satu metode stokastik yang dapat digunakan untuk menyelesaikan permasalahan deterministik seperti perhitungan integral lipat. Metode Monte Carlo bekerja dengan menggunakan sejumlah besar bilangan random untuk mendapatkan pendekatan penyelesaian.

Dalam tulisan ini dibahas mengenai pendekatan Metode Monte Carlo untuk penyelesaian perhitungan integral lipat dengan menggunakan pendekatan perhitungan volume prisma di bawah kurva. Perhitungan integral lipat fungsi sebarang $\mathrm{z}=\mathrm{f}(\mathrm{x}, \mathrm{y})$ atas daerah $R: a \leq x \leq b, c \leq y \leq d$ didekati dengan perhitungan integral lipat fungsi $f+$ dan fungsi $f-$, yaitu fungsi-fungsi non negatif bagian dari fungsi $f$.

Dari hasil program simulasi Monte Carlo yang dibuat dilakukan percobaan untuk menghitung integral lipat beberapa fungsi dua variabel, $z=f(x, y)$. hasil percobaan disimpulkan bahwa metode Monte Carlo memberikan hasil yang mendekati nilai yang sebenarnya (hasil analitis) untuk jumlah titik random di atas 1000 .
\end{abstract}

Kata kunci: Integral Lipat, Simulasi, Metode Monte Carlo.

\section{Pendahuluan}

Integral merupakan topik dalam kalkulus yang banyak diaplikasikan pada matematika maupun pada bidang-bidang lainnya terutama untuk pengembangan ilmu fisika maupun teknik. Perhitungan integral tentu fungsi kontinu pada selang tertutup termasuk dalam permasalahan deterministik. Model-model deterministik telah banyak dikembangkan untuk menyelesaikan permasalahan perhitungan integral tentu fungsi kontinu pada selang tertutup. Beberapa model tersebut antara lain adalah: Metode Romberg, Metode Trapesium, Metode Persegi Panjang dan metode - metode yang lain. Metode-metode tersebut termasuk dalam algoritma komputasional yang menggunakan proses deterministik karena menghasilkan keluaran yang pasti (bahkan bisa juga sama), setiap kali proses perhitungan dijalankan. Perhitungan integral yang termasuk 
permasalahan deterministik dapat juga diselesaikan dengan menggunakan pendekatan stokastik, salah satunya dengan menggunakan Metode Monte Carlo.

Metode Monte Carlo (atau Percobaan Monte Carlo) merupakan salah satu kelas dalam algoritma komputasional yang menggunakan pengambilan sampel secara random untuk menghasilkan penyelesaian permasalahan. Metode Monte Carlo termasuk dalam model stokastik karena dikerjakan dengan menggunakan bilangan-bilangan random dan statistik probabilitas untuk menyelesaikan permasalahan-permasalahan. Metode Monte Carlo dapat juga digunakan untuk menyelesaiakan permasalahan-permasalahan pada bidang ekonomi, fisika, matematika maupun bidang-bidang yang lain.

Dalam tulisan ini disampaikan hasil pembuatan program simulasi Monte Carlo untuk menghitung integral lipat dua fungsi $z=f(x, y)$ atas persegi panjang R. Di dalam program Simulasi Monte Carlo yang dibuat dapat ditentukan berapa banyak bilangan random yang akan digunakan dalam satu percobaan. Rata-rata dari setiap percobaan yang dilakukan dapat memberikan pendekatan hasil penyelesaian dari permasalahan. Ketepatan penyelesaian dapat dilakukan dengan memperbanyak jumlah bilangan random yang digunakan atau pun memperbanyak jumlah percobaan. Untuk melihat kinerja dari program simulasi yang dibuat, maka dilakukan pengujian program terhadap perhitungan integral lipat untuk beberapa fungsi.

\section{Perhitungan Integral Lipat Dua menggunakan Perhitungan Volume}

Dalam tulisan ini integral lipat dua dari fungsi non negatif $z=f(x, y)$ atas daerah $R$ dinyatakan sebagai volume di bawah kurva $z=f(x, y)$ atas daerah $\mathrm{R}$ seperti dinyatakan dalam Definisi 1.

\section{Definisi 1: (Finey Rose, 2000)}

Diberikan fungsi kontinu $z=f(x, y) \geq 0$. Integral lipat fungsi $f$ atas daerah $R$ :a $\leq x \leq b, c \leq y \leq d$ dapat dinyatakan sebagai volume prisma dengan bagian bawah dibatasi oleh $R$ dan bagian atas dibatasi oleh kurva $z=f(x, y)$, seperti dalam Gambar 1. Volume tersebut dapat didefinisikan sebagai

$$
\text { Volume }=\lim _{n \rightarrow \infty} \sum_{k=1}^{n} f\left(c_{k}\right) \Delta x_{k}=\int_{x=a}^{b} \int_{y=c}^{d} f(x, y) d y d x
$$

Dengan kata lain perhitungan integral lipat fungsi kontinu non negatif dapat dilakukan dengan menghitung voluem prisma di bawah kurva atas daerah yang diberikan.

Selanjutnya, untuk menghitung integral lipat suatu fungsi kontinu, yang tidak harus non negatif, digunakan dua bagian fungsi dari f, yaitu fungsi $f^{+}$dan fungsi $f^{-}$. 
Definisi 2: (Royden, 1989)

Diberikan fungsi kontinu $\mathrm{f}$. Bagian positif $f^{+}$dari sebuah fungsi $f$ adalah fungsi

$$
f^{+}=\left\{\begin{array}{l}
f(x), \text { jika } f(x) \geq 0 \\
0, \text { jika } f(x)<0
\end{array}\right. \text {. }
$$

Bagian negatif $f^{-}$dari sebuah fungsi $f$ adalah fungsi

$$
f^{-}=\left\{\begin{array}{l}
-f(x), \text { jika } f(x) \leq 0 \\
0, \text { jika } f(x)>0
\end{array}\right.
$$

Jelas bahwa $f^{+}$dan $f^{-}$merupakan fungsi-fungsi non negatif. Jika $f$ kontinu, maka demikian juga $f^{+}$dan $f^{-}$kontinu. Diperoleh untuk setiap fungsi $f$ berlaku:

$f=f^{+}-f^{-}$

Dengan menggunakan dua bagian fungsi $f$ ini, diperoleh juga bahwa suatu fungsi $f$ dikatakan terintegral atas daerah $R$ jika $f^{+}$dan $f^{-}$keduanya terintegral atas daerah $R$, dan berlaku:

$$
\iint_{R} f(x, y) d x=\iint_{R} f^{+}(x, y) d x-\iint_{R} f^{-}(x, y) d x
$$

Jadi untuk menghitung integral lipat dua dari fungsi kontinu $f$ dapat dilakukan dengan menghitung selisih antara volume di bawah kurva $f^{+}$dengan volume di bawah kurva $f^{-}$.

\section{Metode Monte Carlo untuk Menghitung Volume di bawah kurva.}

Misalkan diberikan fungsi kontinu non negatif $z=f(x, y)$ yang memenuhi $f(x, y) \leq \mathrm{M}$ pada daerah $R: a \leq x \leq b, c \leq y \leq d$, dengan $\mathbf{M}$ suatu konstanta yang merupakan batas atas fungsi $f$, seperti diberikan dalam Gambar 1. 


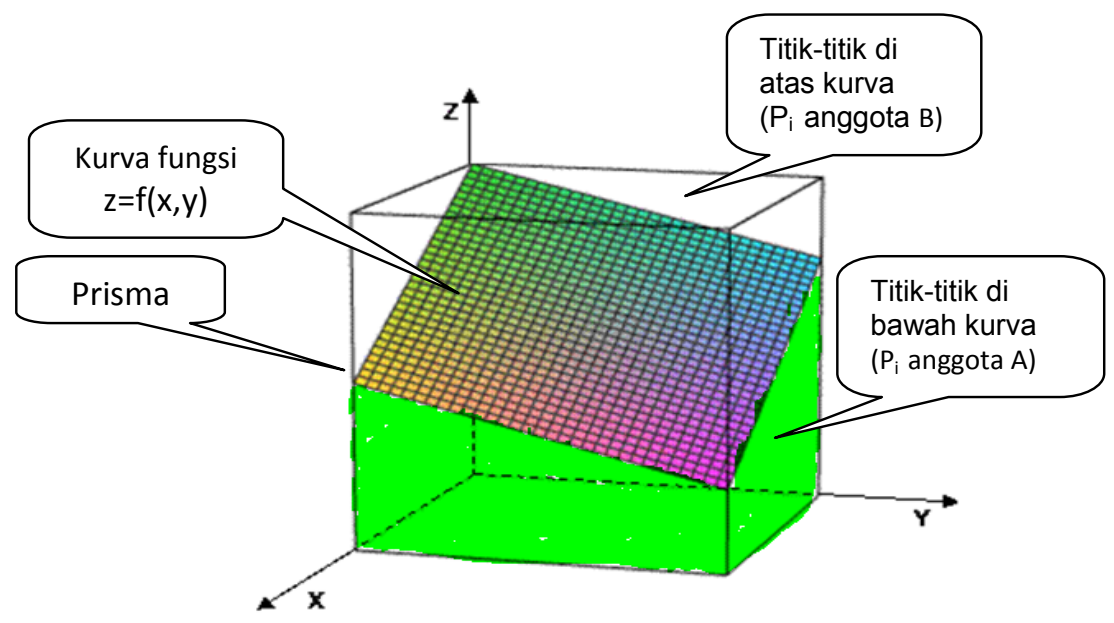

Gambar 1. Ilustrasi Volume di bawah kurva

Perhitungan volume di bawah kurva $z=f(x, y)$ atas persegi panjang $R$ dapat dilakukan dengan metode Monte Carlo berikut ini.

Dilakukan pengambilan titik-titik secara acak $P_{i}\left(x_{i}, y_{i}, z_{i}\right)$ pada daerah prisma dengan alas $R$ dan batas atas $M$. Dilakukan pengujian terhadap titik $P_{\mathrm{i}}$ apakah berada di bawah kurva $z=f(x, y)$, yaitu apakah berlaku $z_{i} \leq f\left(x_{i}, y_{i}\right)$. Jika jawabannya ya, maka titik $P_{i}$ dimasukkan dalam himpunan $A$, yaitu himpunan titik-titik yang berada di bawah kurva. Jika jawabannya tidak, maka titik $P_{\mathrm{i}}$ dimasukkan ke dalam himpunan $\mathrm{B}$, yaitu himpunan titik-titik yang berada di atas kurva. Volume di bawah kurva $z=f(x, y)$ atas daerah $R$ dapat dihitung dengan menggunakan rumus berikut:

$\frac{\text { Volume }}{\text { Volume Prisma }}=\frac{|\mathrm{A}|}{|\mathrm{A} \cup \mathrm{B}|}=\frac{\text { jumlah titik di bawah kurva }}{\text { jumlah titik acak yang diambil }}$, atau

$\begin{aligned} \text { Volume yang dicari }= & \left(\frac{\text { jumlah titik di bawah kurva }}{\text { jumlah titik acak yang diambil }}\right) \times \text { Volume Prisma } \\ & =\left(\frac{\text { jumlah titik di bawah kurva }}{\text { jumlah titik acak yang diambil }}\right) \times(M \times(b-a) \times(d-c))\end{aligned}$

Dengan melakukan modifikasi terhadap metode perhitungan volume di bawah kurva non negatif atas daerah $R$ akan dibuat suatu algoritma untuk menghitung volume daerah yang dibatasi oleh kurva $z=f(x, y)$ (tidak harus non negatif) atas daerah $R$ yang dapat digunakan untuk menghitung integral lipat atas daerah $R$. 


\section{Implementasi dan Pembahasan}

Algoritma berikut ini memberikan urutan perhitungan yang dibutuhkan untuk pembuatan program Simulasi Monte Carlo untuk perhitungan integral lipat dua fungsi $z=f(x, y)$ atas daerah persegi panjang $R: a \leq x \leq b, c \leq y \leq d$.

Input: - banyaknya bilangan random yang akan dibangkitkan $=n$

- fungsi kontinu $z=f(x, y)$ yang akan dihitung

- daerah persegi panjang $R: a \leq x \leq b, c \leq y \leq d$

- batas atas fungsi $z=f(x, y)$, yaitu zMaks.

- batas bawah fungsi $z=f(x, y)$, yaitu zMin.

Output: Nilai integral lipat dua fungsi $z=f(x, y)$ atas daerah $R$ : $a \leq x \leq b, c \leq y \leq d$.

Proses:

Langkah 1: Inisialisasi counter, yaitu: zPosIn=zPosIn=0;

Langkah 2: untuk $\mathrm{i}=1,2,3, \ldots \ldots ., n$, kerjakan langkah 3 sampai dengan 5 .

Langkah 3: bangkitkan bilangan random $x_{i}$, dan $y_{i}$ yang memenuhi $a \leq x_{i} \leq b, c \leq y_{i} \leq d$.

Langkah 4: hitung nilai $z_{i}=f\left(x_{i}, y_{i}\right)$.

Langkah 5:jika $z_{i}>=0$, maka kerjakan langkah 5.1, jika tidak kerjakan langkah 5.2.

Langkah 5.1: Bangkitkan bilangan random z di dalam selang [0, zMaks]. Jika nilai $z \leq z_{i}$, maka tambahkan counter zPosIn dengan satu, jika tidak, maka biarkan counter zPosIn tetap apa adanya.

Langkah 5.2: Bangkitkan bilangan random z di dalam selang [zMin,0]. Jika nilai z>=zi, maka tambahkan counter zNegln dengan satu, jika tidak, maka biarkan counter zNegln tetap apa adanya.

Langkah 6: hitung fPos= zMaks $\times(b-a) \times(d-c) \times \mathrm{zPos} I n / n$, dan

$$
\mathbf{f N e g}=(-1) \times \mathrm{zMin} \times(b-a) \times(d-c) \times \mathrm{zNegln} / n \text {. }
$$

Langkah 7: hitung integral lipat dua: Hasil = fPos $-\mathbf{f N e g}$

Langkah 9: Output: hasil integral lipat dua fungsi $z=f(x, y)$ atas R adalah Hasil.

STOP. 
Keterangan variabel yang digunakan:

- $\quad$ zPosIn: counter untuk menghitung titik-titik yang berada di bawah kurva $f^{+}$

- $\quad$ zNegIn: counter untuk menghitung titik-titik yang berada di bawah kurva $f^{-}$

- $\quad$ fPos: Nilai integral lipat fungsi $f^{+}$

- $\quad$ fNeg: Nilai integral lipat fungsi $f^{-}$

Hasil implementasi program simulasi monte carlo diberikan dalam Gambar 2.

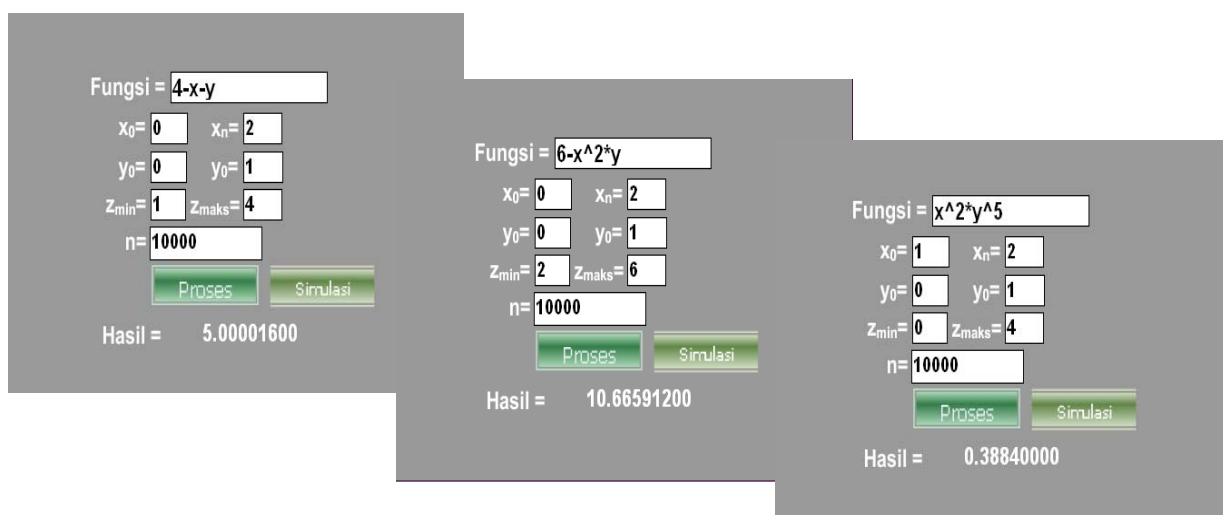

Gambar 2. Contoh program simulasi

Perbandingan antara perhitungan secara analitis dengan hasil percobaan penggunaan program simulasi Monte Carlo (yang dibuat dengan menggunakan ActionScript 3.0) terhadap beberapa fungsi kontinu $z=f(x, y)$ diberikan dalam Tabel 1.

Tabel 1. Tabel hasil percobaan.

\begin{tabular}{|c|c|c|c|c|c|c|}
\hline \multirow{2}{*}{ No } & \multirow{2}{*}{ Kasus } & \multirow{2}{*}{$\begin{array}{l}\text { Hasil } \\
\text { analitis }\end{array}$} & \multicolumn{4}{|c|}{$\begin{array}{l}\text { Hasil percobaan dengan jumlah bilangan random } \\
\text { (n) }\end{array}$} \\
\hline & & & 10 & 100 & 1000 & 10000 \\
\hline 1 & $\int_{x=0}^{3} \int_{y=0}^{2}(2-y) d y d x$ & 6 & 6,048 & 6,0744 & 5,98392 & 6,00072 \\
\hline 2 & $\int_{x=-2}^{2} \int_{y=0}^{4}(2-y) d y d x$ & 0 & 0,128 & $-0,3168$ & $-0,0672$ & $-0,028128$ \\
\hline
\end{tabular}




\begin{tabular}{|l|r|r|r|r|r|r|}
\hline 3 & $\int_{x=0}^{2} \int_{y=0}^{1}(4-x-y) d y d x$ & 5 & 5,072 & 4,9648 & 4,9848 & 5,000016 \\
\hline 4 & $\int_{x=0}^{4} \int_{y=0}^{3}(4-x-y) d y d x$ & 6 & 5,892 & 6,2592 & 5,9574 & 6,019908 \\
\hline 5 & $\int_{x=0}^{2} \int_{y=0}^{1}\left(6-x^{2} y\right) d y d x$ & 10,66667 & 10,728 & 10,7196 & 10,68168 & 10,665912 \\
\hline 6 & $\int_{x=-2}^{0} \int_{y=0}^{1}\left(6-x^{2} y\right) d y d x$ & 18,66667 & 18,472 & 18,448 & 18,55776 & 18,5644560 \\
\hline 7 & $\int_{x=1}^{2} \int_{y=0}^{1}\left(x^{2} y^{5}\right) d y d x$ & 0,388889 & 0,372 & 0,382 & 0,39516 & 0,3884 \\
\hline
\end{tabular}

Catatan: Setiap soal nomor dilakukan percobaan simulasi 100 kali dengan diambil rata-ratanya.

Dari Tabel 1, diperoleh bahwa semakin banyak titik random yang digunakan, yaitu sebanyak 1000 ke atas, maka hasil program simulasi cenderung semakin mendekati nilai yang sebenarnya (hasil analitis).

\section{Penutup}

Berdasarkan hasil implementasi program dan percobaan seperti dalam Tabel 1, maka metode Monte Carlo dapat digunakan untuk menghitung nilai integral lipat dua fungsi dua variabel atas daerah persegi panjang. Semakin banyak titik random yang digunakan, hasil program simulasi cenderung semakin mendekati nilai yang sebenarnya. Dapat disimpulkan bahwa nilai yang diperoleh dari simulasi program ini sudah mendekati nilai yang sebenarnya. Selanjutnya bisa dilakukan penelitian penggunaan metode monte carlo untuk menghitung integral lipat atas daerah non persegi panjang. Dapat juga dicoba untuk penghitungan integral polar pada fungsi polar. 


\section{Daftar Pustaka}

[1] Bradley, Gerald L., 1995, "Calculus”, Prentice-Hall, Inc.

[2] Ensley, Douglas, and Kaskosz, Barbara, "Flash and Math Applets: Learn by Example", http://www.flashandmath.com

[3] Giordano, Frank R., Weir, Maurice D., and Fox, W., 1997, “ A First course in Mathematical Modelling", $2^{\text {nd }}$ ed., Brook/Cole Publishing Company.

[4] Haryono, Nugroho Agus, 2004, "Simulasi Monte Carlo untuk Perhitungan Integral Tentu", Jurnal Informatika Vol I, No 1. Universitas Kristen Duta Wacana.

[5] Heizer, Jay and Render, Barry, 1999, “Operation Management", $5^{\text {th }}$ ed., Prentice-Hall, Inc.

[6] Rose, Finey L., and, 2000, “Calculus A Complete Course”, Addison Wesley.

[7] Royden, H.L., 1989, "Real Analysis”, $3^{\text {rd }}$ ed., Macmillan Publishing Company. 